\title{
Climate response to imposed solar radiation reductions in high latitudes
}

\author{
M. C. MacCracken ${ }^{1}$, H.-J. Shin ${ }^{2,3}$, K. Caldeira ${ }^{2}$, and G. A. Ban-Weiss ${ }^{2,4}$ \\ ${ }^{1}$ Climate Institute, 900 17th St. NW, Suite 700, Washington, DC 20006, USA \\ ${ }^{2}$ Carnegie Institution for Science, Dept. of Global Ecology, 260 Panama Street, Stanford, CA 94305, USA \\ ${ }^{3}$ Ocean Circulation and Climate Research Division, Korea Institute of Ocean Science and Technology (KIOST), \\ 787Haean-ro, Sangnok-gu, Ansan-si, Gyeonggi-do, 426-744, South Korea \\ ${ }^{4}$ Department of Civil and Environmental Engineering, University of Southern California, Los Angeles, CA 90089, USA
}

Correspondence to: M. C. MacCracken (mmaccrac@comcast.net)

Received: 18 July 2012 - Published in Earth Syst. Dynam. Discuss.: 26 July 2012

Revised: 8 July 2013 - Accepted: 20 July 2013 - Published: 2 September 2013

\begin{abstract}
With human-induced climate change leading to amplified warming in high latitudes, mitigation alone is unlikely to be rapid enough to prevent significant, even irreversible, impacts. Model simulations in which solar insolation was arbitrarily reduced poleward of 51,61 , or $71^{\circ}$ latitude in one or both hemispheres not only cooled those regions, but also drew energy from lower latitudes, exerting a cooling influence over much of the particular hemisphere in which the reduction was imposed. The simulations, conducted using the National Center for Atmospheric Research's CAM3.1 atmospheric model coupled to a slab ocean, indicated that high-latitude reductions in absorbed solar radiation have a significantly larger cooling influence than solar reductions of equivalent magnitude spread evenly over the Earth. This amplified influence occurred primarily because concentrated high-latitude reductions in solar radiation led to increased sea ice fraction and surface albedo, thereby amplifying the energy deficit at the top of the atmosphere as compared to the response for an equivalent reduction in solar radiation spread evenly over the globe. Reductions in incoming solar radiation in one polar region (either north or south) resulted in increased poleward energy transport during that hemisphere's cold season and shifted the InterTropical Convergence Zone (ITCZ) away from that pole, whereas comparable solar reductions in both polar regions resulted in increased poleward energy transport, but tended to leave the ITCZ approximately in place. Together, these results suggest that, until emissions reductions are sufficient to limit the warming influence of increasing greenhouse gas
\end{abstract}

concentrations, polar reductions in solar radiation, if they could be efficiently and effectively implemented, warrant further research as an approach to moderating the early stages of both high-latitude and global warming.

\section{Introduction}

Increases in the atmospheric concentrations of carbon dioxide and other radiatively active substances have initiated changes in the global climate that are projected to become substantially larger in the future (IPCC, 2007a; NRC, 2010). Not only are surface temperatures increasing, but significant shifts are also being observed in mean and extreme precipitation, drought, sea level, extent and duration of snow cover and sea ice, ocean acidification, and more (IPCC, 2007a; Blunden and Arndt, 2012). Taken together, these changes are starting to adversely impact water resources, agriculture, terrestrial and aquatic ecosystems, coastal infrastructure, and human health (IPCC, 2007b).

In the Arctic, the amplified temperature increase in high latitudes is accelerating the loss of land and sea ice (ACIA, 2004; AMAP, 2011), which is contributing to sea level rise around the world (IPCC, 2007a; Meier et al., 2007). The extra solar energy being absorbed by darker ocean waters during the sunlit season appears, in turn, to be contributing to changes in the atmospheric circulation and weather in high and mid-latitudes in following seasons (Francis and Vavrus, 2012; Overland et al., 2012). Acceleration of the loss of mass 
from the Antarctic Ice Sheet is also contributing to global sea level rise, and the potential for a catastrophic collapse of the West Antarctic Ice Sheet cannot be ruled out (Truffer and Fahnestock, 2007; Rahmstorf, 2007)

The UN Framework Convention on Climate Change adopted in 1992 and the follow-on Kyoto Protocol negotiated in 1997 were intended to cut growth in global emissions, but have had only limited success (IPCC, 2007c; Helm, 2008). As a result, global greenhouse gas emissions have continued to increase (Friedlingstein et al., 2010; IEA, 2012), and atmospheric concentrations are projected to continue to increase for at least the next several decades, if not longer (IPCC, 2007c). Unless aggressive efforts are made to reduce greenhouse gas emissions, global average temperature is projected to increase by at least $2-3{ }^{\circ} \mathrm{C}$ by the latter decades of the 21 st century, with warming continuing into the 22 nd century (Meinshausen et al., 2009; PIK, 2012). With this much warming, the probability of disruptive and even "dangerous" impacts to the environment and society, even presuming plausible actions to adapt, is likely to increase significantly (Lenton et al., 2008; PIK, 2013).

Even before it became apparent that cutting emissions is unlikely to constrain climate change enough to avoid significant societal and environmental impacts, suggestions have been made that an alternative, or complementary, approach, referred to most often as geoengineering might be needed and feasible. Initial suggestions for counter-balancing the warming influences of greenhouse gases were made in the 1960s (PSAC, 1965; Budyko, 1969, 1974) and received significant attention beginning in the 1990s (NAS, 1992; Leemans et al., 1995; Flannery et al., 1997; Keith, 2000; Schneider, 2001). These early proposals, however, were not followed up with detailed research and engineering studies, mainly because of expectations that emissions reductions could be undertaken rapidly enough to halt ongoing global warming (Crutzen, 2006).

Discouraged by the lack of progress in international negotiations to limit greenhouse gas emissions, Wigley (2006) and Crutzen (2006) resurrected the call for geoengineering research. Since their papers, a number of high-level review groups have called for increased research to determine the potential strengths and weaknesses of proposed approaches and to examine the ethical, governance, and other implications of conducting such research (e.g. Shepherd et al., 2009; Asilomar Scientific Organizing Committee, 2010; GAO, 2010; Rayner et al., 2010; Long et al., 2011).

Approaches to geoengineering (although perhaps more appropriately labeled climate engineering) can be divided into two broad categories (e.g. Shepherd et al., 2009; Caldeira et al., 2013). The first is to increase the rate of removal of $\mathrm{CO}_{2}$ and other greenhouse gases from the atmosphere (generally referred to as carbon dioxide reduction, or CDR), which will not be treated in this paper. The second is to reduce the uptake and retention of energy by the Earth system, with most of these focused on reducing the amount of solar radiation so that this category is generally referred to as solar radiation management (SRM). Mitchell and Finnegan (2009), however, have suggested that regional or global surface temperature could also be lowered by reducing the global coverage of cirrus clouds, thereby increasing emission of longwave radiation to space rather than reducing incoming solar radiation. Shepherd et al. (2009) and Caldeira et al. (2013) provide recent overviews of possible approaches.

With rapidly changing conditions in the Arctic creating the potential for significant impacts around the world (ACIA, 2004) and mitigation unlikely to be rapid enough to avert such impacts, the potential that climate engineering could play a role has been raised (Khan et al., 2001; Lane et al., 2007). While Arctic cooling could be accomplished as part of global-scale climate engineering (Govindasamy and Caldeira, 2000; Rasch et al., 2008b, 2009), global climate engineering raises a long list of concerns about unintended consequences and governance and implementation challenges (e.g. Bala et al., 2008; Robock, 2008; Robock et al., 2009). To potentially moderate the unintended consequences, a number of studies have started to explore whether imposing solar reductions in more directed ways, such as varying the latitudinal pattern of the solar reduction, might reduce at least some of the concerns and consequences of a full global intervention (Lane et al., 2007; Caldeira and Wood, 2008 (hereafter CW2008); Robock et al., 2008; MacMartin et al., 2013).

In this paper, we extend this analysis in a conceptual manner, considering the potential for reductions in solar radiation in the Arctic and Antarctic separately and together as a means of counter-balancing high latitude climate change while exerting a modest cooling influence on middle and lower latitudes. Section 2 describes the model and solar reduction scenarios used in our conceptual study. Section 3 presents the results of the model simulations, comparing and contrasting the effects of making the solar reductions in the two polar regions separately and together. Section 4 compares the modelestimated effectiveness of moderating global warming by reducing incoming solar radiation in the polar regions versus reducing solar radiation uniformly over the globe. Section 5 then discusses the relative strengths and weaknesses of the polar approach and section 6 presents the conclusions and possible implications of this study and describes shortcomings that merit further investigation.

\section{Solar reduction scenarios}

In that this study builds on simulations and results reported in CW2008, we also used Version 3.1 of the National Center for Atmospheric Research (NCAR) Community Atmosphere Model (Collins et al., 2006). The overall model configuration was the same, with the model having a horizontal resolution of $2^{\circ}$ in latitude by $2.5^{\circ}$ in longitude and 26 vertical levels. The land surface component (Community Land Model 3.1) calculates energy and water fluxes based 
on surface vegetation, soil moisture, and the $\mathrm{CO}_{2}$ concentration. Although later versions of the NCAR community atmospheric model are being used by participants in the Geoengineering Model Intercomparison (GeoMIP) study (Kravitz et al., 2011), the most critical processes in analysis of the response to reductions in solar radiation will involve changes in large-scale tropospheric dynamics and thermodynamics, including energy exchanges with the surface, and these processes are reasonably represented in this model and welldocumented (Collins et al., 2006).

The atmospheric model in our study is coupled to a slab ocean, as in CW2008. While treating full ocean dynamics and thermodynamics would open an additional response path for the climate system, the meridional ocean fluxes in high latitudes are generally small compared to the atmospheric fluxes, suggesting that the changes in atmospheric dynamics and thermodynamics that are being explicitly treated by the model likely dominate the response. In addition, substantial computer time would be required to accurately simulate equilibrium changes in ocean temperatures and fluxes.

Sea ice cover is calculated in the model based on thermodynamic considerations. While treatment of sea ice movement would likely be an important process to represent in a detailed transient simulation, the large changes in sea ice extent in the scenarios considered in this conceptual study are likely dominated by the thermodynamic terms. However, because of this shortcoming and possible interactions with cloud cover, the results, particularly over the Southern Ocean, should be considered preliminary.

As was done in CW2008, reducing the amount of incoming solar radiation at the top of the atmosphere was used as a surrogate for reducing solar energy uptake. While this is an idealization, technical approaches that have the potential for actually effecting reductions in roughly the defined regions do seem conceivable (see Appendix A). Although the detailed physics and chemistry of actual implementation would likely introduce a number of practical complications (e.g. Rasch et al., 2008a; Robock et al., 2008; Pierce et al., 2010), the purpose of our idealized modeling study is to focus on important qualitative insights and to determine if there is a basis for more detailed scientific and engineering analyses.

We carried out two control simulations to provide the baseline results for considering the effects of polar reductions in polar radiation; the first imposed the preindustrial atmospheric $\mathrm{CO}_{2}$ concentration of $280 \mathrm{ppm}\left(1 \times \mathrm{CO}_{2}\right)$ to represent a world not being affected by human activities, while the second simulation was for a world with a doubled $\mathrm{CO}_{2}$ concentration $\left(2 \times \mathrm{CO}_{2}\right)$, although assuming no change in the extent of the Greenland and Antarctic ice sheets. We then conducted a series of simulations with solar radiation reduced over various domains, each simulation starting from the equilibrium climate for a doubled $\mathrm{CO}_{2}$ concentration.

We first simulated the response to a global reduction in top-of-the-atmosphere (TOA) solar radiation of $1.8 \%$ (named GSRM), a value that was chosen to approximately counterbalance the positive global forcing of a $\mathrm{CO}_{2}$ doubling (CW2008). To examine the effects of polar instead of global reductions, we then separately imposed nine different highlatitude reductions in TOA solar radiation, with the amounts depending on the latitudinal range of the reduction. As detailed in Table 1, three different high-latitude domains in the Northern $(\mathrm{N})$ and Southern (S) Hemispheres were considered, with solar reductions imposed both separately in the two hemispheres and together (NS).

Drawing from results of preliminary simulations (not reported here), the percentage reductions in each latitude band were chosen to roughly counterbalance the calculated warming in the Arctic from a doubling of the $\mathrm{CO}_{2}$ concentration (CW2008). The particular scenarios selected and then imposed on both the Northern and Southern Hemispheres were: $25 \%$ reduction in TOA solar insolation poleward of $71^{\circ}(71 \mathrm{p} 25), 10 \%$ reduction poleward of $61^{\circ}(61 \mathrm{p} 10)$, and $6 \%$ poleward of $51^{\circ}(51 \mathrm{p} 06)$. Two of the Northern Hemisphere cases (i.e. the $10 \%$ (N61p10) and $25 \%$ (N71p25) reductions) are the same as the simulations Arctic61_0.37 and Arctic71_0.37 of CW2008. To determine the quasiequilibrium response, each of the simulations was carried out for 100 model years, with the first $40 \mathrm{yr}$ discarded and the last $60 \mathrm{yr}$ used in the analysis. For purposes of comparison of the global and regional effectiveness of each scenario, we also have calculated regional and global sensitivities (reported in Sect. 4).

\section{Temperature and precipitation responses to the reductions in solar radiation}

Figure 1a shows the equilibrium, annual-average temperature response of the model to a doubling of the atmospheric $\mathrm{CO}_{2}$ concentration. This is the same result as shown in CW2008, and results in a global warming of $2.23^{\circ} \mathrm{C}$, ranging from a bit under $2{ }^{\circ} \mathrm{C}$ over most of the world's oceans and to over $4{ }^{\circ} \mathrm{C}$ in the Arctic and Antarctic regions. While this is a bit lower climate sensitivity than the mean of most full oceanatmosphere climate models, the results show the same general characteristics, including polar amplification and greater change over the land than the oceans. For the purposes of this conceptual study, using the same model as for CW2008 ensures the results from that study can be compared to the new simulations with reductions in Antarctic solar radiation. Of course, simulations with more complete and updated models will be needed if these conceptual simulations suggest polar reductions alone may be an effective approach to counterbalancing the significant warming and loss of land ice in the Arctic and Antarctic regions.

Starting from the climatic conditions with doubled $\mathrm{CO}_{2}$, Fig. $1 \mathrm{~b}$ shows that reduction of solar insolation by $1.8 \%$ reduces global warming by $2.04{ }^{\circ} \mathrm{C}$, or by over $90 \%$ of the observed warming. The induced cooling is larger in the polar 
Table 1. Global and regional mean reductions in solar insolation and climate sensitivity for the various perturbation simulations. The baseline simulation with doubled $\mathrm{CO}_{2}$ had a concentration of $560 \mathrm{ppm}$ and a solar constant of $1366 \mathrm{Wm}^{-2}$. Details of the calculations of climate sensitivity are described in Appendix B.

\begin{tabular}{|c|c|c|c|c|c|}
\hline \multirow{2}{*}{$\begin{array}{l}\text { Simulations with } \\
560 \mathrm{ppm} \mathrm{CO}_{2} \text { and } \\
\text { specified reduction } \\
\text { in solar insolation }\end{array}$} & \multirow{2}{*}{$\begin{array}{l}\text { Change in solar insolation } \\
\text { and the region where the } \\
\text { change was applied }\end{array}$} & \multicolumn{2}{|c|}{$\begin{array}{l}\text { Instantaneous change in } \\
\text { top-of-atmosphere solar } \\
\text { forcing }\left(\mathrm{Wm}^{-2}\right)^{-1}, \\
\text { positive downward }\end{array}$} & \multicolumn{2}{|c|}{$\begin{array}{l}\text { Climate sensitivity } \\
\mathrm{K}\left(\mathrm{Wm}^{-2}\right)^{-1}\end{array}$} \\
\hline & & $\begin{array}{l}\text { Global } \\
\text { average }\end{array}$ & $\begin{array}{r}\text { Average over } \\
\text { the region } \\
\text { where the } \\
\text { forcing was } \\
\text { applied }\end{array}$ & $\begin{array}{c}\text { Global } \\
\text { sensitivity }\end{array}$ & $\begin{array}{l}\text { Sensitivity } \\
\text { within the } \\
\text { region } \\
\text { where the } \\
\text { forcing was } \\
\text { applied }\end{array}$ \\
\hline \multicolumn{6}{|c|}{ Global solar radiation management (GSRM) simulation } \\
\hline GSRM & $\begin{array}{l}1.8 \% \text { reduction uniformly } \\
\text { over the entire globe }\end{array}$ & -4.14 & -4.14 & 0.49 & 0.49 \\
\hline \multicolumn{6}{|c|}{ Northern Hemisphere high-latitude forcing simulations } \\
\hline N51p06 & $\begin{array}{l}6 \% \text { reduction over the } \\
\text { latitudes north of } 51^{\circ} \mathrm{N}\end{array}$ & -0.77 & -6.86 & 0.69 & 1.45 \\
\hline N61p10 & $\begin{array}{l}10 \% \text { reduction over the } \\
\text { latitudes north of } 61^{\circ} \mathrm{N}\end{array}$ & -0.57 & -9.05 & 0.69 & 1.91 \\
\hline N71p25 & $\begin{array}{l}25 \% \text { reduction over the } \\
\text { latitudes north of } 71^{\circ} \mathrm{N}\end{array}$ & -0.52 & -19.07 & 0.76 & 1.77 \\
\hline \multicolumn{6}{|c|}{ Southern Hemisphere high-latitude forcing simulations } \\
\hline S51p06 & $\begin{array}{l}6 \% \text { reduction over the } \\
\text { latitudes south of } 51^{\circ} \mathrm{S}\end{array}$ & -0.75 & -6.70 & 1.41 & 1.77 \\
\hline S61p10 & $\begin{array}{l}10 \% \text { reduction over the } \\
\text { latitudes south of } 61^{\circ} \mathrm{S}\end{array}$ & -0.53 & -8.41 & 1.65 & 4.27 \\
\hline S71p25 & $\begin{array}{l}25 \% \text { reduction over the } \\
\text { latitudes south of } 71^{\circ} \mathrm{S}\end{array}$ & -0.43 & -15.59 & 1.49 & 1.05 \\
\hline \multicolumn{6}{|c|}{ Northern and Southern Hemisphere high-latitude forcing simulations } \\
\hline NS51p06 & $\begin{array}{l}6 \% \text { reduction over the } \\
\text { latitudes north of } 51^{\circ} \mathrm{N} \\
\text { and south of } 51^{\circ} \mathrm{S}\end{array}$ & -1.51 & -6.78 & 1.03 & 1.53 \\
\hline NS61p10 & $\begin{array}{l}10 \% \text { reduction over the } \\
\text { latitudes north of } 61^{\circ} \mathrm{N} \\
\text { and south of } 61^{\circ} \mathrm{S}\end{array}$ & -1.09 & -8.73 & 1.14 & 2.51 \\
\hline NS71p25 & $\begin{array}{l}25 \% \text { reduction over the } \\
\text { latitudes north of } 71^{\circ} \mathrm{N} \\
\text { and south of } 71^{\circ} \mathrm{S}\end{array}$ & -0.94 & -17.33 & 1.08 & 1.28 \\
\hline
\end{tabular}

regions than in low and mid-latitudes, confirming that polar amplification occurs for both warming and cooling. Figure 1c uses $1 \times \mathrm{CO}_{2}$ as a base to show that the residual warming is small over virtually all regions, with statistically significant warming greater than $1^{\circ} \mathrm{C}$ remaining only in the Arctic and a few areas around Antarctica where ice extent and duration are not fully restored.
Figure 2 shows the amount of cooling that is generated by the three scenarios involving Arctic reductions of solar radiation. For these cases, the reductions in temperature are, not surprisingly, concentrated in high northern latitudes and not statistically significant in the Southern Hemisphere. While the reductions in Arctic temperatures were intended to be similar for the three simulations, there is a larger global response for the solar reduction reaching down to $51^{\circ} \mathrm{N}$, a 


\section{Change in Annual Mean Surface Air Temperature (K)}
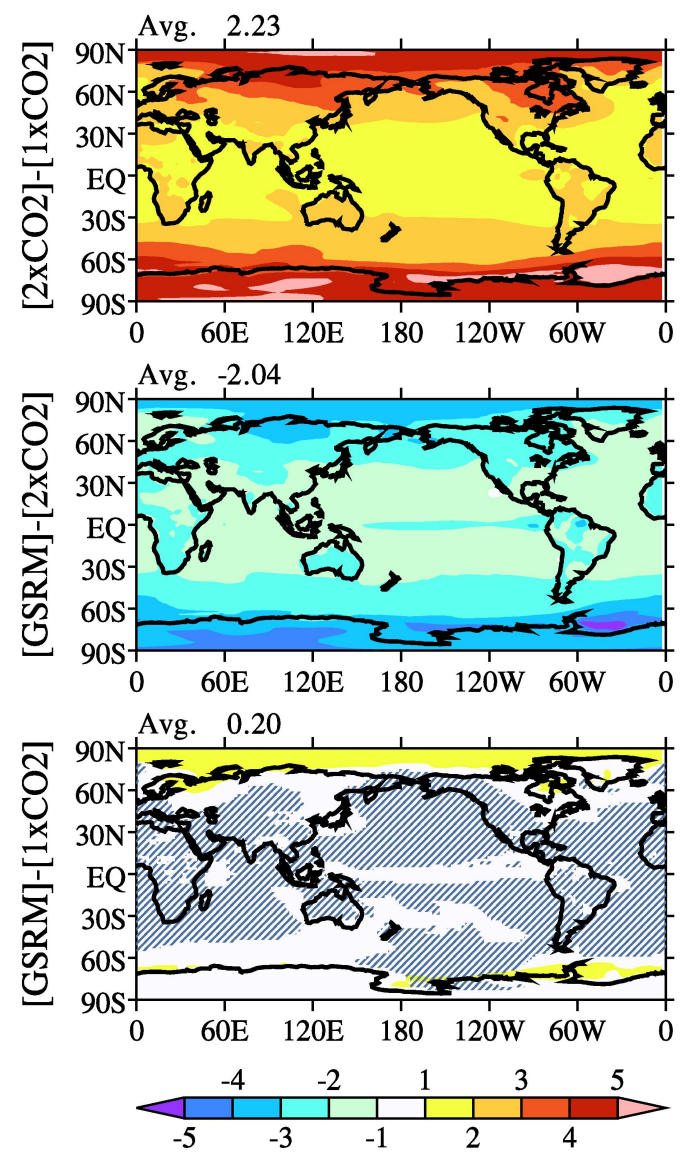

Fig. 1. Model-calculated changes in climatological annual-mean surface air temperature (in Kelvins) in response to specified changes in radiative forcing. The top figure shows the temperature change for $2 \times \mathrm{CO}_{2}$ as compared with $1 \times \mathrm{CO}_{2}$, indicating that the warming in high latitudes is $2-3$ times the warming in low latitudes. The middle figure shows the temperature change that results from imposing a globally uniform reduction in insolation of $1.8 \%$ starting from the $2 \times \mathrm{CO}_{2}$ baseline, showing changes in high latitudes considerably larger than in low latitudes. The bottom figure shows the remaining temperature change as a result of imposing the $\mathrm{CO}_{2}$ doubling and a $1.8 \%$ global reduction in insolation. The hatching indicates areas where the changes are not statistically significant at the $95 \%$ confidence level using a modified Student's $t$ test for autocorrelated data (Zwiers and von Storch, 1995).

result of more effectively inducing ice-albedo feedback, as discussed in the next section.

Figure 3 displays the latitudinal profiles of temperature change for the nine polar reduction scenarios ( 3 for reductions at each pole and 3 for reductions at both poles), and compares these results to the temperature change achieved with a global reduction in solar radiation. Poleward of about $60^{\circ}$ in each hemisphere, the polar reductions in solar radiation cause about the same decrease in annual-average temperature, with the reductions in the two hemispheres
Climatological Annual Mean Surface Air Temperature (K)
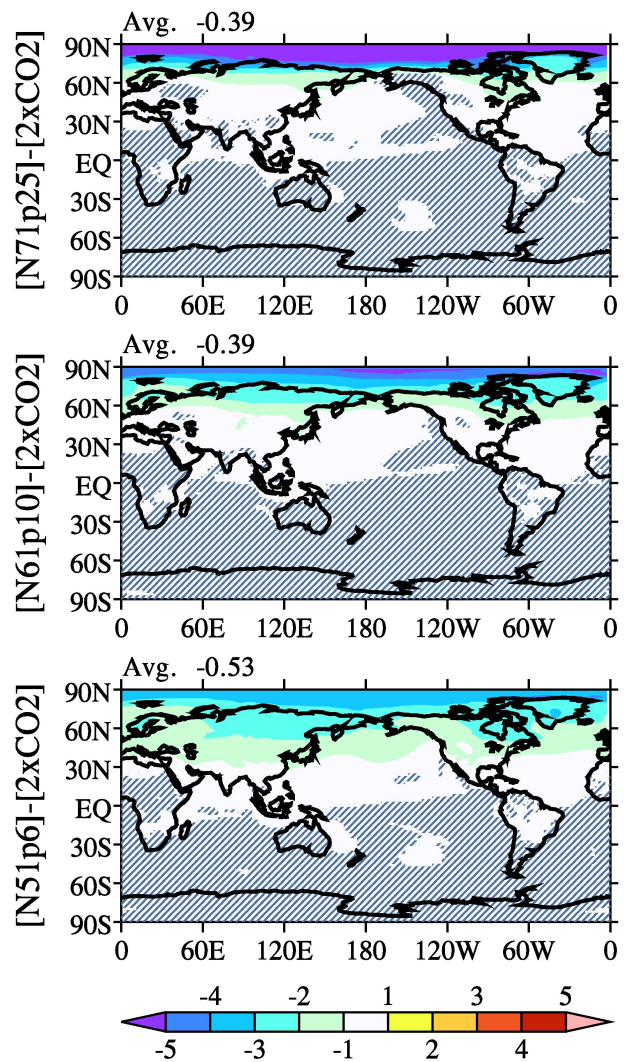

Fig. 2. Model-calculated changes in annual-mean surface air temperature (in Kelvins) from the doubled- $\mathrm{CO}_{2}$ baseline as a result of imposing northern high-latitude solar reductions of 3 different latitudinal extents on a $\mathrm{CO}_{2}$ doubled climate. From the top, the solar reductions are $25 \%$ north of $71^{\circ} \mathrm{N}, 10 \%$ north of $61^{\circ} \mathrm{N}$, and $6 \%$ north of $51^{\circ} \mathrm{N}$. The hatching, mostly in the Southern Hemisphere, covers regions where there is no statistically significant effect, as explained in the caption for Fig. 1.

together being roughly equal to the sum of the decreases in each polar region separately. That there are some differences among the various polar cases suggests that it would be possible to do some refining of the response by adjusting both the extent and the intensity of the reductions in the two hemispheres. Compared to the simulation for the global solar reduction, the polar reduction simulations not surprisingly result in a reduced cooling influence in mid-latitude regions, and considerably less response in low latitudes.

Figure 4 presents the same results, but as the warming remaining relative to $1 \times \mathrm{CO}_{2}$. The curve showing the warming for a $\mathrm{CO}_{2}$ doubling shows a latitudinal variation from about $1.5^{\circ} \mathrm{C}$ in low latitudes to several times that much in polar regions. While solar reductions in one hemisphere tend to compensate (or even over-compensate) for the polar amplification of $\mathrm{aCO}_{2}$ doubling, they generate only a modest response in low and mid-latitudes and virtually no reduction 


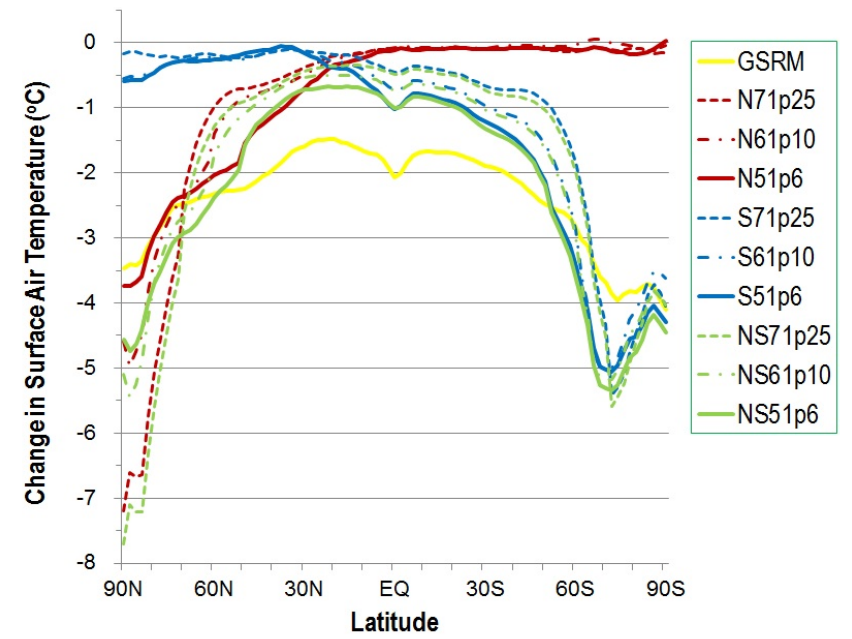

Fig. 3. Latitudinal variation of the change in temperature (in Kelvins) induced by the set of the ten global and polar solar reduction simulations. The plot is linear in latitude to provide improved resolution in high latitudes; an equal area weighting would show that the simulations with polar reductions in solar radiation are more tightly restricted to polar regions and that the global reduction cools a much larger fraction of the Earth than the polar reductions.

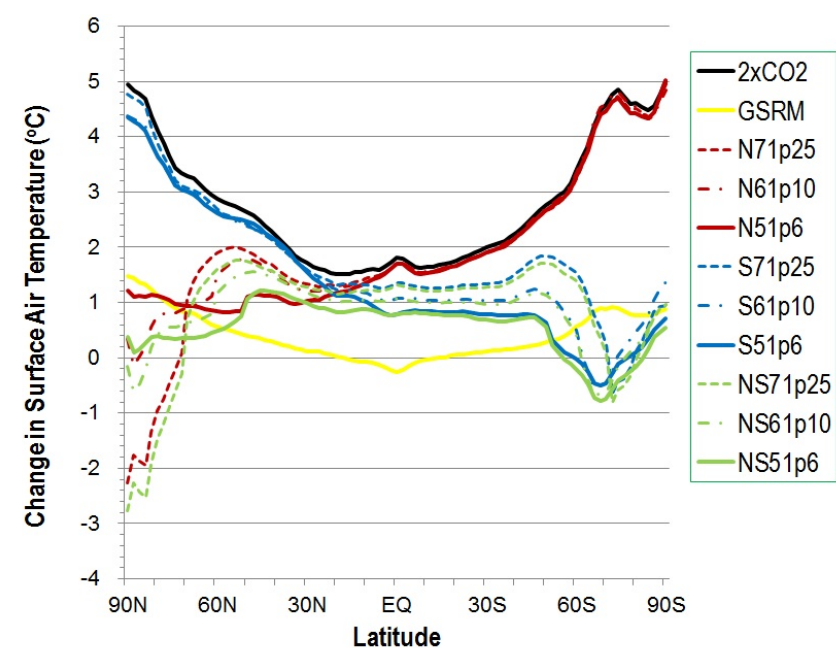

Fig. 4. Latitudinal variation of the temperature change (in Kelvins) remaining after imposing both a $\mathrm{CO}_{2}$ doubling and the ten different extents of solar reduction considered in this paper. The plot is linear in latitude to provide improved resolution in high latitudes; an equal area weighting would show that counter-balancing of the warming in the simulations with polar reductions in solar radiation are more tightly restrained to the high latitudes where the reductions were imposed, and that a global reduction in solar radiation is required to return mid- and low-latitude temperature increases to near their $1 \times \mathrm{CO}_{2}$ values.

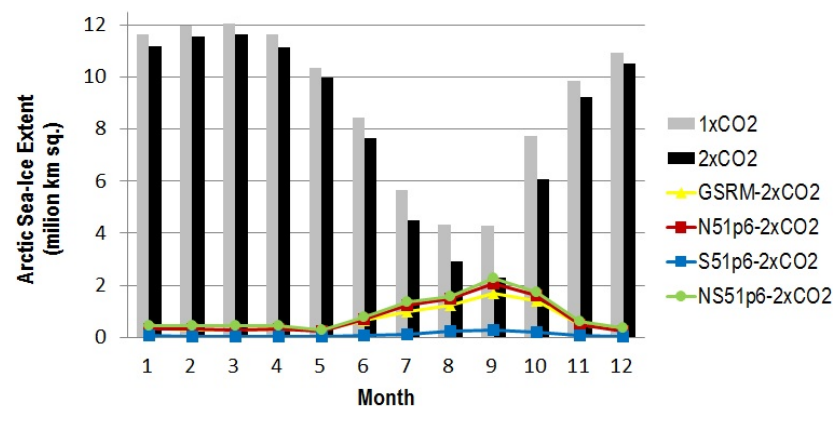

Fig. 5. Monthly variation in Arctic sea ice extent (in millions of $\mathrm{km}^{2}$ ) for $1 \times \mathrm{CO}_{2}$ and $2 \times \mathrm{CO}_{2}$ and the calculated increments in Arctic sea ice that would result from a $1.8 \%$ reduction in global solar radiation or from $6 \%$ reductions in solar radiation from $51^{\circ}$ latitude to the pole in the Northern, Southern, or both Hemispheres, showing that reducing solar radiation by these amounts would, as intended, have the effect of essentially restoring Arctic sea ice cover.

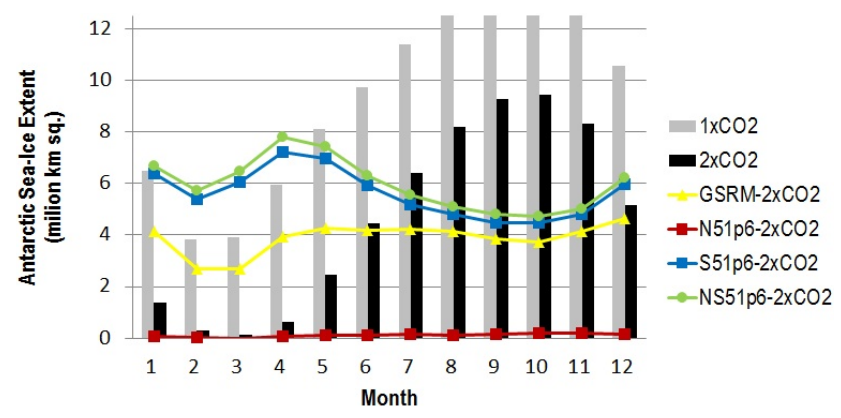

Fig. 6. Monthly variation in Antarctic sea ice extent (in millions of $\mathrm{km}^{2}$ ) for $1 \times \mathrm{CO}_{2}$ and $2 \times \mathrm{CO}_{2}$ and the calculated increments in Antarctic sea ice that would result from a $1.8 \%$ reduction in global solar radiation or from $6 \%$ reductions in solar radiation from $51^{\circ}$ latitude to the pole in the Northern, Southern, or both Hemispheres, showing that reducing solar radiation by these amounts would, as intended, have the effect of essentially restoring Antarctic sea ice cover, perhaps even overcompensating.

in temperature in the other hemisphere. Imposed together, however, solar reductions in the two hemispheres, although their responses are primarily polar, reduce global warming for a $\mathrm{CO}_{2}$ doubling to roughly $1{ }^{\circ} \mathrm{C}$.

Figure 5 shows the effects of the various reductions on the extent of monthly average Arctic sea ice extent for a $\mathrm{CO}_{2}$ doubling and for the three solar reduction scenarios involving changes reaching from $51^{\circ} \mathrm{N}$ to the poles. For the baseline case of $\mathrm{a} \mathrm{CO}_{2}$ doubling, the model generates a reduction in Arctic sea ice extent during the summer and fall that is reflective of the model's lower climate sensitivity as compared to other climate models. Imposing solar reductions in the Northern Hemisphere tends to restore sea ice coverage; reducing solar radiation in the Southern Hemisphere, on the other hand, has virtually no influence on Arctic sea ice cover.

Figure 6 presents comparable results for changes in sea ice around Antarctica. Here, the doubling of the $\mathrm{CO}_{2}$ 

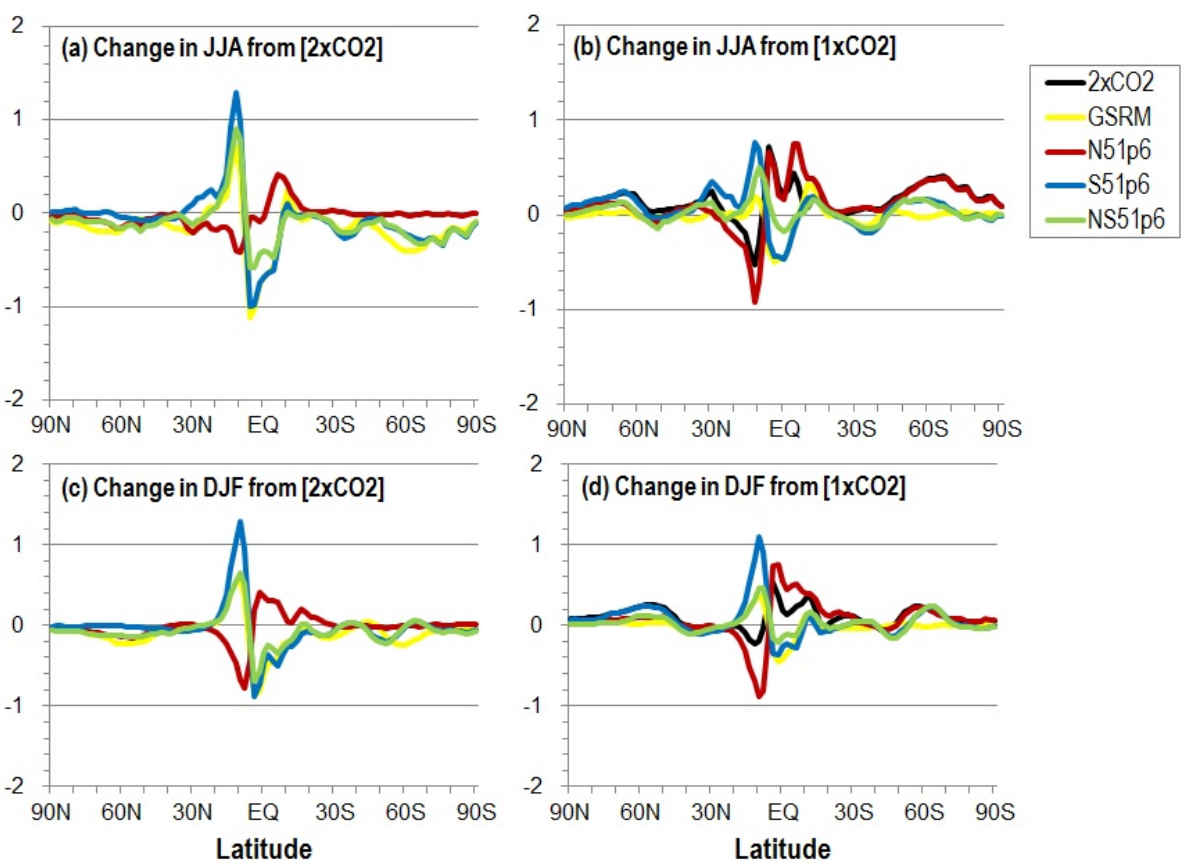

Fig. 7. Latitudinal distribution of the differences in precipitation (in mm day ${ }^{-1}$ ) for June-July-August (JJA - top panels) and DecemberJanuary-February (DJF - bottom panels) that would result after imposing both a $\mathrm{CO}_{2}$ doubling and solar reductions of either $1.8 \%$ globally or $6 \%$ reductions in solar radiation from $51^{\circ}$ latitude to the pole in the Northern, Southern, or both Hemispheres. The left column shows the effect of the solar reductions from the $2 \times \mathrm{CO}_{2}$ simulation and the right column from the $1 \times \mathrm{CO}_{2}$ baseline.

concentration has caused a much larger retreat of summer sea ice. Polar reductions in solar radiation lead to essentially a full restoration of the Southern Ocean sea ice cover, even perhaps over-compensating, suggesting that a smaller solar reduction would be sufficient. On the other hand, the $1.8 \%$ global reduction in solar radiation was able to fully offset lower latitude increases in surface temperature, but was somewhat short of restoring full Antarctic sea ice cover.

Figure 7 shows the latitudinal response of precipitation. Figure $7 \mathrm{~b}$ and $\mathrm{d}$ show that the effect of the $\mathrm{CO}_{2}$ doubling is primarily a southward shift of the annual average of the Inter-tropical Convergence Zone (ITCZ), causing changes of about $0.5 \mathrm{~mm} \mathrm{day}^{-1}$, positive just to the south of the equator and negative to the north; these changes amount to about $10 \%$ of the precipitation that is occurring at these latitudes in the control simulation. Whereas Bala et al. (2008) see a suppression of global precipitation from global imposition of global solar reduction, we do not see this occurring as a result of polar reductions.

Figure 7a and c show that effects of the reductions in solar radiation also have their primary effect at tropical latitudes, a result of this region being the source of energy for the natural deficit in net TOA radiation in high latitudes. Reducing solar radiation in the Arctic leads to a further shift of low latitude precipitation to the south, again by about $0.5 \mathrm{~mm} \mathrm{day}^{-1}$, whereas reducing solar radiation in the Antarctic region (or even in both regions) leads to an even greater shift of the rains to the Northern Hemisphere. Returning to Fig. $7 \mathrm{~b}$ and d, the case with only an Arctic solar reduction exacerbates the precipitation perturbation caused by the $\mathrm{CO}_{2}$ doubling, whereas the case with comparable solar reductions in both hemispheres somewhat counterbalances the precipitation shift, leaving the net perturbation at a few percent of the model calculated average precipitation at low latitudes. The main conclusion suggested by these model results is that polar solar reductions can affect low latitude precipitation, and that the particular choice of reduction can either moderate or exacerbate the shift caused by the effects of the $\mathrm{CO}_{2}$ doubling.

Figure 8 presents similar results for snowfall. Solar reductions in the Arctic have the effect of restoring snowfall in Northern Hemisphere high latitudes, but this does not fully occur for the latitudes just to the south of the zone of solar reduction. In the Southern Hemisphere, the reduction in solar radiation essentially restores wintertime (JJA) snowfall as effectively as occurred with a global reduction in solar radiation. Reducing solar radiation in both polar regions counterbalanced the effects of the $\mathrm{CO}_{2}$ doubling in these areas.

These results are similar to those reported by CW2008, who found that polar reductions in solar radiation do not generally diminish the increase in high-latitude precipitation caused by the doubled $\mathrm{CO}_{2}$ concentration. This is the case because polar solar reductions do not reduce radiation reaching the surface at latitudes where ocean surface heating drives evaporation and land surface heating (along with other 

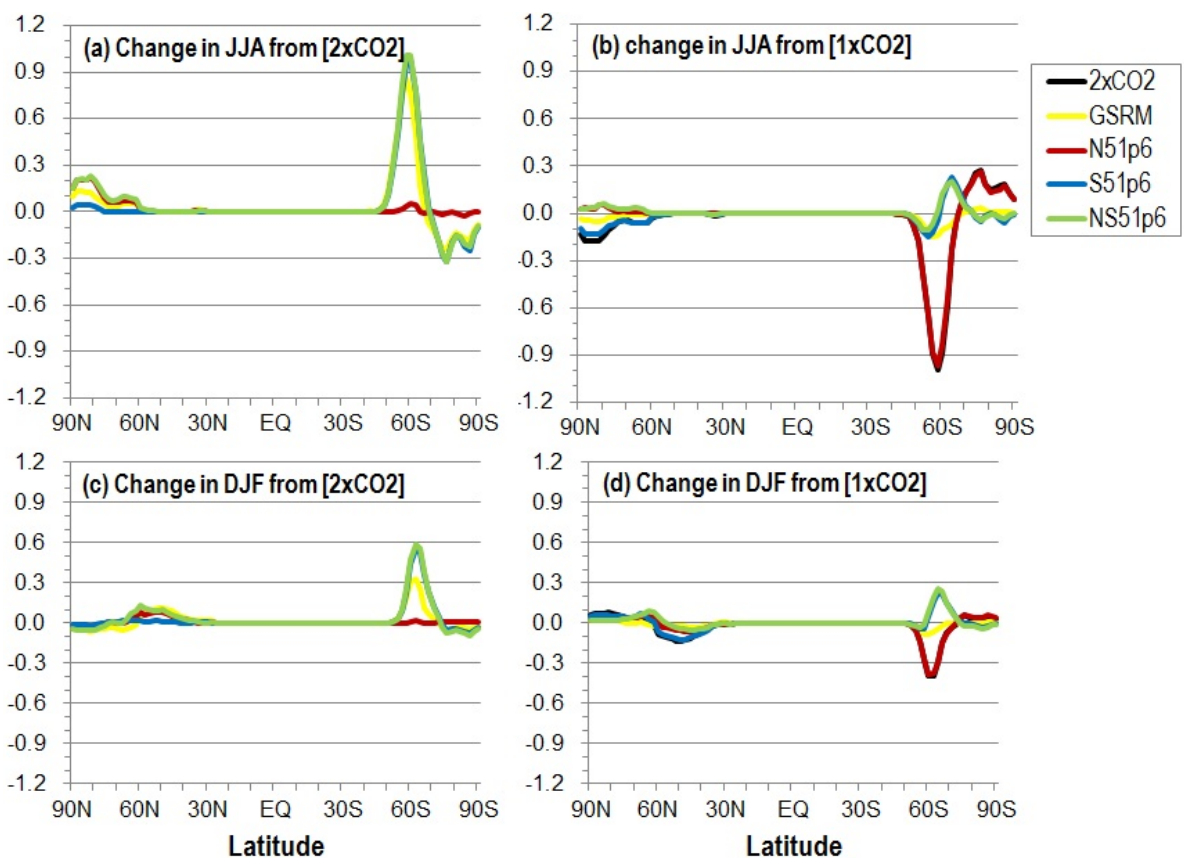

Fig. 8. Latitudinal distribution of the differences in snowfall (in $\mathrm{mm} \mathrm{day}^{-1}$ of precipitation) for June-July-August (JJA - top panels) and December-January-February (DJF - bottom panels) that would result after imposing both a $\mathrm{CO}_{2}$ doubling and solar reductions of either $1.8 \%$ globally or $6 \%$ reductions in solar radiation from 51 degrees latitude to the pole in the Northern, Southern, or both Hemispheres. The left column shows the effect of the solar reductions from the $2 \times \mathrm{CO}_{2}$ simulation and the right column from the $1 \times \mathrm{CO}_{2}$ baseline. Note expanded scale compared to Fig. 7.

factors) drives the monsoon circulation. In addition, the different results for the various reduction scenarios suggest the potential for adjusting the effects on mid-latitude precipitation patterns, as discussed in a related study by Ban-Weiss and Caldeira (2010).

\section{Relative effectiveness of the alternative solar reduction extents}

To quantitatively compare the relative counter-balancing effectiveness of polar and global reductions in solar radiation, we have normalized the temperature response for each simulation by calculating the global and regional sensitivities when starting from doubled $\mathrm{CO}_{2}$ equilibrium; details are provided in Appendix B. Figure 9 compares the global-scale sensitivities of several parameters (specifically, the normalized changes in global mean surface air temperature, TOA albedo for clear and all-sky conditions, ice fraction, and cloud fraction per unit change in radiative forcing) for each of the solar reduction simulations. Each of the simulations led to a decrease in surface air temperature and an increase in ice fraction that, in turn, led to an increase in the TOA clear-sky albedo. However, the cloud response in the simulations was dependent on the particular latitudinal extent of the reduction in solar radiation. In the globally uniform solarreduction simulation, the increase in clear-sky albedo due to the increase in ice fraction was offset by a reduction in cloud fraction, such that the TOA all-sky albedo remained roughly unchanged.

In the northern high-latitude solar reductions, the all-sky albedo decreased. This occurred because cloud cover decreased such that the cloudy sky albedo decrease was larger than the increase in clear sky albedo. In the southern highlatitude solar reductions, however, the cloud fraction increased along with the ice fraction, leading to an increase in all-sky TOA albedo. The increases in both cloud and ice fractions thus contributed to a higher climate sensitivity for the southern than for the northern high-latitude solar reductions.

Table 1 compares the numerical results from the simulations, showing that the global climate sensitivity for the global solar reduction in our simulation is roughly $0.5 \mathrm{~K}$ $\left(\mathrm{Wm}^{-2}\right)^{-1}$, whereas the global climate sensitivities for the high-latitude solar reductions range from 0.7 to $1.7 \mathrm{~K}$ $\left(\mathrm{Wm}^{-2}\right)^{-1}$. By contrast, Robock et al. (2008) found that, normalized by mass, their global injection had an effectiveness about $60 \%$ greater than for their polar injection; had the high latitude injections been mainly for the 4 months of peak solar radiation in the Arctic, the relative effectiveness might well be closer to the results found in this study.

The high polar sensitivities that we find indicate an amplification of the direct effect of the change in solar radiation through interactions with the underlying geography. Primarily because of the strong response of Southern Ocean sea 

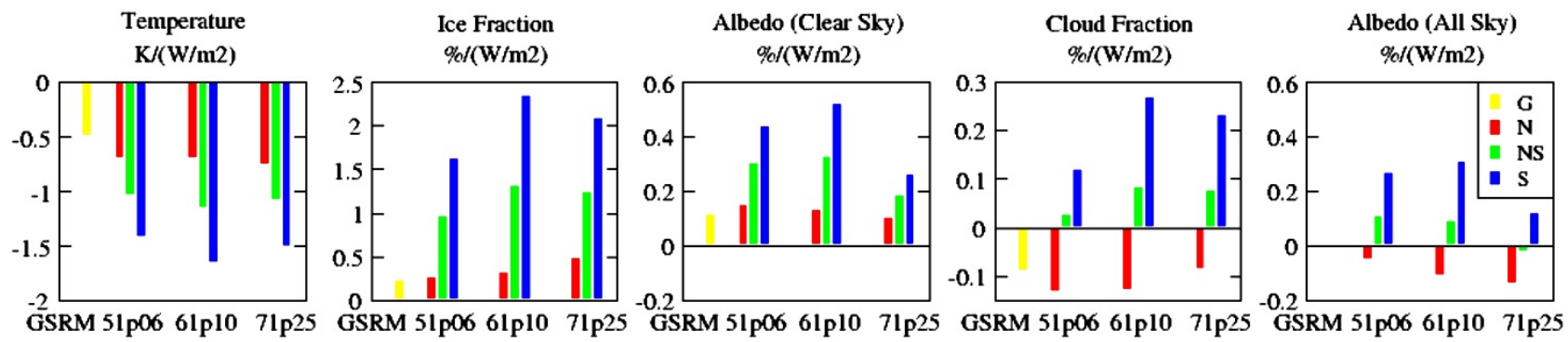

Fig. 9. Global mean changes in surface air temperature, ice fraction, TOA albedo for clear skies, cloud fraction, and TOA all-sky albedo, with each normalized by dividing by the reduction in solar forcing averaged over the globe. The yellow bars represent the results from the globally uniform reduction in solar insolation $(\mathrm{G})$, the red bars from the northern high-latitude insolation reductions $(\mathrm{N})$, the blue bars from the southern high-latitude insolation reductions (S), and the green bars from combined northern and southern high-latitude solar reductions (NS). For the three high-latitude reduction cases, incident solar radiation at the TOA was reduced by $6 \%$ poleward of $51^{\circ}, 10 \%$ poleward of $61^{\circ}$, and $25 \%$ poleward of $71^{\circ}$.

ice, which averaged about $2 \mathrm{~K}\left(\mathrm{Wm}^{-2}\right)^{-1}$, and associated changes in cloud cover of about a tenth of this value, the global climate sensitivity for southern-latitude solar reductions of roughly $1.5 \mathrm{~K}\left(\mathrm{Wm}^{-2}\right)^{-1}$ and the change in global average temperature were about double that for northern solar reductions, even though the climate sensitivity and temperature changes within the two regions were similar. As indicated by the temperature responses to the separate and combined reductions in northern and southern high-latitude solar radiation, the climate sensitivities for high-latitude solar reductions appear to be roughly additive (cf. Ban-Weiss and Caldeira, 2010), suggesting that solar reductions in different latitude bands might be linearly scalable to match the changing intensity of the greenhouse gas induced radiative forcing.

To determine the regional climate sensitivity (i.e. the normalized response for the regions where the solar reduction was imposed), we calculated the change in the regional energy balance for the northern and southern solar reductions (see Appendix B). As indicated in Table 1, the S61p10 simulation (i.e. $10 \%$ reduction in TOA solar insolation poleward of $61^{\circ} \mathrm{S}$ ) exhibited the largest regional climate sensitivity (i.e. $>4 \mathrm{~K}\left(\mathrm{Wm}^{-2}\right)^{-1}$ in this region). In contrast, the regional climate sensitivity for $\mathrm{S} 71 \mathrm{p} 25$ was less than that for the similar northern forcing (i.e. N71p25). These hemispheric and latitudinal differences are associated with the differing land-ocean distributions and associated differences in surface albedo, as well as the different potential for spreading of sea ice and changes in cloud cover. In the Arctic, sea ice is confined by geography to be mostly north of $70^{\circ} \mathrm{N}$, although in winter it can reach toward $\sim 40^{\circ} \mathrm{N}$ in some regions.

Around Antarctica, however, sea ice extent can be present from $\sim 80$ to $\sim 60^{\circ} \mathrm{S}$ and, due to the absence of land, can therefore increase in area more than can occur for Arctic solar reductions. In our simulations, the larger reduction in the net energy balance for the Southern as compared to the Northern Hemisphere led to a sharper meridional temperature gradient and a greater pull of energy from

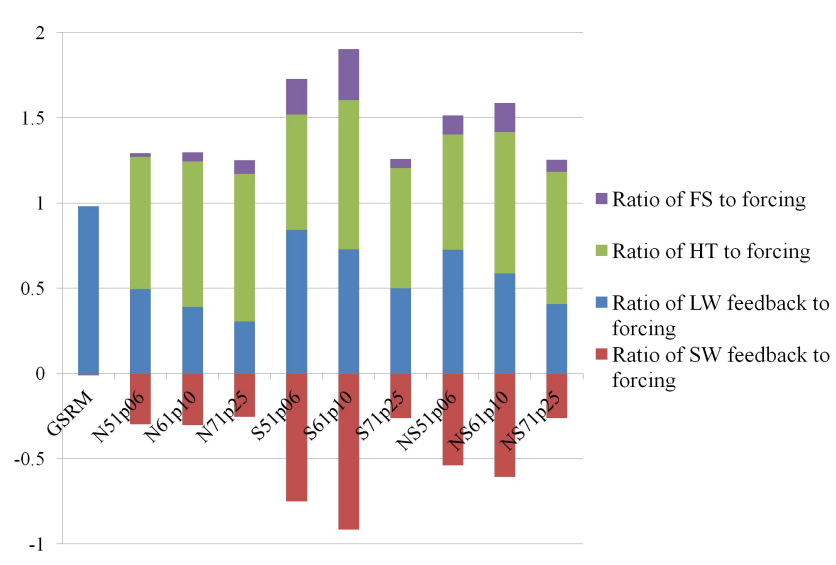

Fig. 10. Changes in the atmospheric energy balance in the region where the solar reduction was imposed, normalized by the region's reduction in shortwave radiative forcing. The terms shown are for the net change in the surface-to-atmosphere heat flux (FS), the atmospheric horizontal heat flux into the region (HT), the net longwave energy flux (LW), and the net change in shortwave radiation (SW).

middle and low latitudes. Although our model does not account for adjustments in ocean transport and movement of sea ice that might, in part, compensate, Southern Hemisphere solar reductions led to a larger cooling outside the polar region than for identical solar reductions in the Northern Hemisphere, with the southern reductions so strong that they even induced some cooling in the Northern Hemisphere (see Fig. 3).

Figure 10 compares the changes in energy flux terms for the various simulations. Longwave ( $\mathrm{LW}$ ) feedback is defined as the change in net longwave radiation at the TOA, and the shortwave (SW) feedback as the change in net shortwave radiation at the TOA minus the imposed radiative forcing. For the globally uniform solar reduction, equilibrium requires that longwave radiation change to balance the TOA change in solar radiation (hence, a ratio of 1). For the high-latitude 
solar reduction cases, however, for which the analysis considers only the changes within the region where the solar reduction is imposed, the LW and SW terms need not balance because of contributions from horizontal transport (HT) and surface exchange (FS). In the polar regions, the positive shortwave feedback due mainly to increased sea ice extent is similar in magnitude to the longwave feedback due to the insulating effects of increased sea ice extent. Because of the combined energy reduction that results, meridional heat flux convergence increases. Compared to the regional sensitivity in other regions, the high regional sensitivity for the S61p10 reduction resulted from the greater potential for changes in sea ice extent (reflected in the relatively large value of the change in the surface flux - FS), making this region the most efficient location for imposing solar reductions, at least in terms of induced temperature change.

\section{Discussion}

Although idealized, our calculations do indicate that solar reductions in polar regions have the potential to counterbalance warming in these regions and at least some of the warming in the middle latitudes of the same hemisphere; when imposed together, simultaneous reductions in both hemispheres have the potential to partially counterbalance warming in polar regions and into lower latitudes in each hemisphere. In considering this potential, however, caveats to the analysis must be noted. First, the analysis is based on equilibrium simulations and carried out using an atmospheric model atop a slab ocean. More definitive exploratory simulations are needed using a full Earth system model that includes an interactive ocean and to examine the potential for counterbalancing gradual warming with gradually intensifying solar reductions.

Second, the simulations are idealized, being based on simply reducing the amount of solar radiation rather than actually enhancing reflection of clouds and/or increasing aerosol loading. Robock et al. (2008), using a global climate model with interactive stratospheric chemistry, carried out simulations comparing the temperature responses to stratospheric injections of $\mathrm{SO}_{2}$ into the Arctic and into the tropical stratosphere. They concluded that the Arctic injection would lead to cooling as far south as $30^{\circ} \mathrm{N}$ and weaken the summer monsoons over Africa and Asia, just as was the case for tropical injections. The extent to which these lower latitude changes were due to the spread of sulfate aerosols out of the Arctic, however, is not clear. In addition, their $\mathrm{SO}_{2}$ injections extended through the full year, including through the polar night, which likely increased the likelihood that the sulfate could spread, and overestimated the amount needed to counterbalance warming in the Arctic alone. Our simulations suggest that, on a latitudinal average basis, except for shifting the ITCZ, confining the counter-balancing effect to the high latitudes has limited effects on precipitation outside the region of the solar reduction.

While some warming remains in our simulations for both the global and high-latitude solar reductions, appropriately adjusting the magnitude and extent of the various highlatitude solar reductions might, for example, make it possible to induce temperature reductions and precipitation shifts that would both promote regrowth of the sea ice cover and counteract mass loss from glaciers and ice sheets. With warming of the Southern Ocean being critical in loss of ice mass from Antarctic ice shelves (Pritchard et al., 2012), simultaneously counter-balancing warming in both hemispheres seems to reduce the $\mathrm{CO}_{2}$-induced changes in the particular hemisphere it is applied, and to reduce the impact on the ITCZ from reducing solar radiation in the opposite hemisphere. That such adjustments in the ITCZ might be feasible is also suggested by idealized aqua-planet simulations conducted by Kang et al. (2008) using an atmospheric GCM coupled to a slab ocean. Those simulations investigated the consequences of an imposed heating in the extratropics, finding that the ITCZ shifted poleward into the warmed hemisphere.

Several paleoclimate simulations have also indicated that a shift in the ITCZ could result from differential hemispheric forcing. For example, a southward shift was found during the Last Glacial Maximum when the Northern Hemisphere was more strongly cooled than the Southern Hemisphere (Koutavas and Lynch-Stieglitz, 2004; Broccoli et al., 2006). Although the forcing in those studies was imposed on the surface or in an ocean mixed layer, the TOA forcing in our simulations imposed also resulted in a poleward shift of the ITCZ toward the warmer (or unperturbed) hemisphere.

The greater response of the sea-ice extent (and thus the larger albedo change) resulting from the southern highlatitude solar reduction is also in accord with previous findings. For example, Hall (2004) found that surface-albedo feedback accounts for about $50 \%$ of the warming in high latitudes and is larger in the Southern Hemisphere than in the Northern Hemisphere. Winton (2005) confirmed this result using results from the Coupled Model Intercomparison Project (CMIP3), although the simulated surface warming was greater in the northern high latitudes than in the southern high latitudes because of differences in heat capacity and changes in albedo, strength of the low-lying inversion, and other feedback processes (Winton, 2006).

While our study points out the importance of changes in the extent of Southern Ocean sea ice in determining the regional and global climate response, high confidence cannot be placed in the quantitative response because our simulations were limited by having fixed ocean energy transport and used a thermodynamic sea ice model. Nevertheless, our study demonstrates that different regions may respond very differently to differences in applied forcing.

A number of the shortcomings in the simulations here are being explored in a series of controlled model simulations under the GeoMIP framework (Kravitz et al., 2011), and 
increasingly by studies of particular research groups (Jones et al., 2010). With the prospects for limiting the pace of climate change through near-term emissions reductions, exploring the potential for regionally limited and time-varying changes in forcing would seem to merit greater attention and resources.

\section{Summary and next steps}

The simulations reported here indicate that reductions in solar radiation in polar regions can both counterbalance warming in the regions where the reductions are imposed and somewhat moderate temperature increases in lower latitudes. The results also suggest a potential to moderate and even reverse the mass loss from glaciers and ice sheets because the increase in high-latitude precipitation caused by the increasing greenhouse gas concentrations is not diminished, similar to the results of CW2008 and Ban-Weiss and Caldeira (2010). With the rate of sea level rise apparently accelerating, rebuilding the mass of polar land ice would seem likely to benefit coastal and island nations around the world.

Were solar reductions in polar regions to actually be considered, the different regional sensitivities in the two hemispheres suggest that deployment would likely involve different extents and intensities in each hemisphere. In the Northern Hemisphere, solar reductions north of the Arctic Circle appear capable of generating a significant temperature reduction without substantial diminution of solar radiation over lower latitudes. In the Southern Hemisphere, reduction of solar radiation over the Southern Ocean would be much more effective than reducing solar absorption over the highly reflective Antarctica ice sheet.

While our simulations have provided a number of initial insights, broader and deeper understanding of relevant processes and interactions will require a more comprehensive research program. In particular, simulations are needed that consider the implications and consequences of plausible approaches for actually reducing solar absorption (e.g. as enumerated in Appendix A). Beyond our equilibrium simulations, simulations are needed in which realistic solar reductions are applied with gradually increasing intensity and the consequences both inside and outside the directly affected regions are compared to the consequences resulting from the projected increases in greenhouse gas concentrations without climate engineering. Such increased understanding has the potential to provide a richer base of information and set of choices for policymakers to consider in seeking to avoid dangerous levels of global climate change.

\section{Appendix A}

\section{Potential approaches for creating a reduction in absorbed solar radiation in polar regions}

This paper uses high-latitude reductions in solar radiation to conduct a technique-independent exploration of the potential for counter-balancing polar climate change. There are, however, several techniques that, separately or together, may have the potential to alter the regional energy balance to a significant degree, even if perhaps not capable of counter-acting the full effects of a $\mathrm{CO}_{2}$ doubling. Drawing from approaches suggested for global SRM, possibilities include increasing stratospheric solar backscatter by augmenting the aerosol concentration in the lower polar stratosphere (Shepherd et al., 2009; Rasch et al., 2008a) and brightening marine stratus clouds by CCN injection (Latham et al., 2008), which could be used either in the polar regions or to cool ocean currents that carry heat into the polar regions.

Two additional possibilities may also merit consideration (MacCracken, 2009, 2011). First, the tropospheric albedo could be increased by re-creating the tropospheric haze layer present during the late 20th century as a result of the sulfur dioxide emissions from power plants in Europe, Russia, and North America; while it would likely best be done by other means, such an aerosol increment would be expected to reduce solar radiation reaching the surface, as may have been happening since at least the 1980s (Valero et al., 1984). Second, surface albedo could be increased by injecting microbubbles (Seitz, 2011) into open water areas such as leads; this could be used to reduce absorption of solar radiation, especially in limited areas that might constrain bubble spread.

Such solar reduction approaches would only need to be used during the third of the year when the Sun is relatively high in the sky (and perhaps for only the period after the albedo of snow atop sea ice has dropped). However, the briefer time period would increase the albedo change that would need to be induced compared to global or larger scale approaches. In addition, because the atmosphere (and ocean, were it included) would tend to mix some of the cooling influence to lower latitudes, there would need to be a further augmentation.

Although not leading to a reduction in absorption of solar energy, approaches that increase loss of infrared radiation could also be used. One example, as proposed by Mitchell and Finnegan (2009), is the injection of ice nuclei into cirrus clouds to disperse the clouds and increase the rate of loss of infrared radiation to space. In addition, the use of icebreakers to break up thin sea ice in the fall and winter might be useful in increasing the transfer of heat from the ocean to the atmosphere, from which it could be radiated to space (M. C. MacCracken, personal communication, 2011). Such ice-breaking would have the effect of thickening the sea ice, which could help to extend its albedo effect further into the spring or summer. 
While the implementation of the proposed approaches, separately or together, would be unlikely to be as precise geographically as the solar reductions imposed in the model, each of the proposed approaches could likely be imposed in a way that would tend to focus the influence within the region. Comparison of the temperature responses to the various extents of the imposed solar reductions (see Figs. 3 and 4) suggests that different boundaries for the forcing would not have a significant impact on the results.

\section{Appendix B}

\section{Estimation of global and regional climate sensitivities}

Global and regional climate sensitivities are calculated as the ratio of temperature change to radiative forcing. Radiative forcing (RF) is conventionally defined as the change in forcing at the tropopause (IPCC, 1994). Because horizontal and vertical gradients of tropopause height make it difficult to extract changes at that level difficult, we use the value at the top of the atmosphere (TOA) as an approximation. For simulations with changes in incoming solar radiation, this approximation gives nearly the same value as making the calculation at the tropopause. This would not be the case were the sensitivity being calculated from simulations involving changes in greenhouse gas concentrations because of the need to account for the effects of rapid adjustment of stratospheric temperatures. While a change in solar radiation could, in principle, cause a change in the stratospheric ozone concentration, an adjustment is not needed in our analyses because the ozone concentration is held fixed. In any case, because the UV-component of solar radiation is only $\sim 3 \%$, the effect of the solar reductions would only involve a limited adjustment.

Based on the annual-average conditions at the start of the simulation, the RF (i.e. change in the TOA energy balance) at a given point $i$ (defined as $F_{i}$ ) is calculated as

$F_{i}=\left(1-\alpha_{i}\right) \Delta S_{i}$,

where $\alpha_{i}$ is the annual-average of the local TOA albedo from the $2 \times \mathrm{CO}_{2}$ control simulation and $\Delta S_{i}$ is the imposed TOA change in the annual-average solar insolation. Global mean $\mathrm{RF}$ is then calculated by integrating over the globe and dividing by global surface area.

Global mean climate sensitivity is calculated by dividing the change in annual-average global mean surface air temperature by the annual-average global mean RF (defined as $\bar{F})$. The global climate sensitivity $(1 / \lambda)$ is thus given by

$\bar{F}=\lambda \Delta \bar{T}$,

where $\Delta \bar{T}$ is the change in global mean surface air temperature.

We also calculated the regional climate sensitivity for the regions where solar insolation was reduced. In calculating this sensitivity, we included consideration of annual-average change in horizontal energy transport, as was done by Boer and $\mathrm{Yu}$ (2003). Whereas Boer and Yu (2003) were successful in using the change in meridional temperature gradient to estimate changes in the energy transport, the situation is more complex with a warming climate. Under such conditions, although there is a decrease in the meridional temperature gradient, the atmospheric poleward energy transport is projected by models to increase due to an increase in sensible energy transport in low latitudes and an increase in latent energy transport in middle and high latitudes (Held and Soden, 2006).

Our analysis of regional climate sensitivity therefore accounts directly for calculated changes in atmospheric meridional energy transport, especially transport into the different high latitude regions where solar insolation is decreased. Doing this required that account be taken of the effects of annual-average changes in meridional energy fluxes and the imposed reduction in solar radiation. To calculate the meridional energy transport $\left(\Delta H_{\varphi}\right)$ at latitude $\varphi$, we ignored changes in annual-mean atmospheric energy storage and then integrated the net horizontal energy flux from the surface to the top of the atmosphere from the pole to the boundary latitude for each of the regional solar reductions. To eliminate spurious, non-zero energy transports at the poles resulting from atmospheric variability, the global average of the net energy flux was subtracted uniformly at all latitudes. Because ocean energy transport is held fixed for the model configuration that we use, only changes in atmospheric meridional energy transport are included in this analysis. The radiative forcing averaged at latitude $\varphi$ thus can be calculated using the relationship (Murphy, 2010):

$F_{\varphi}=\lambda_{\varphi} \Delta T_{\varphi}+\Delta H_{\varphi}$,

where $\lambda_{\varphi}$ is the climate response parameter for the region and $\Delta T_{\varphi}$ is the change in the region's mean surface air temperature relative to the $2 \times \mathrm{CO}_{2}$ control run. The regional climate sensitivity is then defined to be the inverse of $\lambda_{\varphi}$.

Acknowledgements. The views expressed are those of the authors, and not necessarily their sponsoring organizations. H.-J. Shin was supported in part by the Korea Institute of Ocean and Science Technology through project number PE99123. We thank three anonymous reviewers for their constructive comments.

Edited by: G. Bala 


\section{References}

ACIA - Arctic Climate Impact Assessment: Impacts of a Warming Arctic: Arctic Climate Impact Assessment, Cambridge University Press, 140 pp., 2004.

AMAP - Arctic Monitoring and Assessment Programme: Snow, Water, Ice and Permafrost in the Arctic (SWIPA): Climate Change and the Cryosphere, Arctic Monitoring and Assessment Programme, Oslo, 538 pp., 2011.

Asilomar Scientific Organizing Committee (MacCracken, M. (chair), Barrett, S., Barry, R., Crutzen, P., Hamburg, S., Lampitt, R., Liverman, D., Lovejoy, T., McBean, G., Parson, E., Seidel, S., Shepherd, J., Somerville, R., and Wigley, T. M. L.): The Asilomar Conference Recommendations on Principles for Research into Climate Engineering Technologies: Conference Report, Climate Institute, Washington, D.C., 37 pp., 2010.

Bala, G., Duffy, P. B., and Taylor, K. E.: Impact of geoengineering schemes on the global hydrological cycle, P. Natl. Acad. Sci USA, 105, 7664-7669, 2008.

Ban-Weiss, G. A. and Caldeira, K.: Geoengineering as an optimization problem, Environ. Res. Lett., 5, 034009, doi:10.1088/17489326/5/3/034009, 2010.

Blunden, J. and Arndt, D. S., Eds.: State of the Climate in 2011, B. Am. Meteorol. Soc., 93, S1-S264, 2012.

Boer, G. J. and Yu, B.: Climate sensitivity and response, Clim. Dynam., 20, 415-429, doi:10.1007/s00382-002-0283-3, 2003.

Broccoli, A. J., Dahl, K. A., and Stouffer, R. J.: Response of the ITCZ to Northern Hemisphere cooling, Geophys. Res. Lett., 33, L01702, doi:10.1029/2005GL024546, 2006.

Budyko, M. I.: The effect of solar radiation variations on the climate of the Earth, Tellus, 21, 611-619, 1969.

Budyko, M. I.: The method of climate modification, Meteorol. Hydro., 2, 91-97, 1974.

Caldeira, K. and Wood, L.: Global and Arctic climate engineering: Numerical model studies, Philos. T. Roy. Soc. A, 366, 40394056, doi:10.1098/rsta.2008.0132, 2008.

Caldeira, K., Bala, G., and Cao, L.: The science of geoengineering, Annu. Rev. Earth Sci., 41, 231-256, 2013.

Collins, W. D., Bitz, C. M., Blackmon, M. L., Bonan, G. B., Bretherton, C. S., Carton, J. A., Chang, P., Doney, S. C., Hack, J. J., Henderson, T. B., Kiehl, J. T., Large, W. G., McKenna, D. S., Santer, B. D., and Smith, R. D.: The Community Climate System Model Version 3 (CCSM3), J. Climate, 19, 2122-2143, 2006.

Crutzen, P. J.: Albedo enhancement by stratospheric sulfate injections: A contribution to resolve a policy dilemma?, Climatic Change, 77, 211-219, 2006.

Flannery, B. P., Marland, G., Broecker, W., Ishatani, H., Keshgi, H., Komiyama, H., MacCracken, M., Rosenberg, N., Steinberg, M., and Wigley, T. M. L.: Geoengineering Climate, 379-427, Chapter 8, in: The Engineering Response to Climate Change, edited by: Watts, R. G., Lewis Publishers, Boca Raton, 492 pp., 1997.

Francis, J. A. and Vavrus, S. J.: Evidence Linking Arctic Amplification to Extreme Weather in Mid-Latitudes, Geophys. Res. Lett., 39, L06801, doi:10.1029/2012GL051000, 2012.

Friedlingstein, P., Houghton, R. A., Marland, G., Hackler, J., Boden, T. A., Conway, T. J., Canadell, J. G., Raupach, M. R., Ciais, P., and Le Quéré, C.: Update on $\mathrm{CO}_{2}$ emissions, Nat. Geosci., 3, 811-812, doi:10.1038/ngeo1022, 2010.
GAO - Government Accountability Office: A Coordinated Strategy Could Focus Federal Geoengineering Research and Inform Governance Efforts, GAO-10-903, Washington, D.C., 70 pp., 2010.

Govindasamy, B. and Caldeira, K.: Geoengineering Earth's radiative balance to mitigate $\mathrm{CO}_{2}$-induced climatic change, Geophys. Res. Lett., 27, 2141-2144, 2000.

Hall, A.: The role of surface albedo feedback in climate, J. Climate, 17, 1550-1568, 2004.

Held, I. M. and Soden, B. J.: Robust responses of the hydrological cycle to global warming, J. Climate, 19, 5686-5699, 2006.

Helm, D.: Climate-change policy: Why has so little been achieved?, Oxford Rev. Econ. Policy, 24, 211-238, 2008.

IEA - International Energy Agency: $\mathrm{CO}_{2}$ Emissions from Fuel Combustion - Highlights, IEA, Paris, France, 138 pp., 2012.

IPCC - Intergovernmental Panel on Climate Change: Climate Change 1994: Radiative Forcing of Climate Change and an Evaluation of the IPCC IS92 Emission Scenarios, Cambridge, Cambridge University Press, Cambridge, UK, 339 pp., 1994.

IPCC - Intergovernmental Panel on Climate Change: Climate Change 2007: The Physical Science Basis, in: Contribution of Working Group I to the Fourth Assessment Report of the Intergovernmental Panel on Climate Change, edited by: Solomon, S., Qin, D., Manning, M., Marquis, M., Averyt, K., Tignor, M. M. B., Miller Jr., H. L., and Chen, Z., Cambridge University Press, Cambridge and New York, 996 pp., 2007a.

IPCC - Intergovernmental Panel on Climate Change: Climate Change 2007: Impacts, Adaptation and Vulnerability, in: Contribution of Working Group II to the Fourth Assessment Report of the Intergovernmental Panel on Climate Change, edited by: Parry, M., Canziani, O., Palutikof, J., van der Linden, P., and Hanson, C., Cambridge University Press, Cambridge and New York, 976 pp., $2007 \mathrm{~b}$.

IPCC - Intergovernmental Panel on Climate Change: Climate Change 2007: Mitigation, in: Contribution of Working Group III to the Fourth Assessment Report of the Intergovernmental Panel on Climate Change, edited by: Metz, B., Davidson, O., Bosch, P., Dave, R., and Meyer, L., Cambridge University Press, Cambridge and New York, 851 pp., 2007c.

Jones, A., Haywood, J., Boucher, O., Kravitz, B., and Robock, A.: Geoengineering by stratospheric $\mathrm{SO}_{2}$ injection: results from the Met Office HadGEM2 climate model and comparison with the Goddard Institute for Space Studies ModelE, Atmos. Chem. Phys., 10, 5999-6006, doi:10.5194/acp-10-5999-2010, 2010.

Kang, S. M., Held, I. M., Frierson, D. M. W., and Zhao, M.: The Response of the ITCZ to extratropical forcing: Idealized slabocean experiments with a GCM, J. Climate, 21, 3521-3532, doi:10.1175/2007JCLI2146.1, 2008.

Keith, D. W.: Geoengineering the climate: History and prospect, Annu. Rev. Energ. Env., 25, 245-284, 2000.

Khan, E., Ferrell, W., MacCracken, M. C., Schwartz, S. E., Duffy, P. B., Thompson, S., and Marland, G. H.: Response Options to Limit Rapid or Severe Climate Change, Department of Energy, Washington, D.C., 37 pp., 2001.

Koutavas, A. and Lynch-Stieglitz, J.: Variability of the marine ITCZ over the eastern Pacific during the past 30,000 years: Regional perspective and global context, in: The Hadley Circulation: Present, Past, and Future, edited by: Diaz, H. F. and Bradley, R. S., Springer, 347-369, 2004. 
Kravitz, B., Robock, A., Boucher, O., Schmidt, H., Taylor, K., Stenchikov, G., and Schulz, M.: The Geoengineering Model Intercomparison Project (GeoMIP), Atmos. Sci. Lett., 12, 162167, doi:10.1002/asl.316, 2011.

Lane, L., Caldeira, K., Chatfield, R., and Langhoff, S. (Eds.): Workshop Report on Managing Solar Radiation, NASA/CP-2007214558, NASA Center for AeroSpace Information, Hanover, MD, 31 pp., 2007.

Latham, J., Rasch, P. J., Chen, C. C., Kettles, L., Gadian, A., Gettelman, A., Morrison, H., Bower, K., and Choularton, T. W.: Global temperature-stabilization via controlled albedo enhancement of low-level maritime clouds, Philos. T. Roy. Soc. A, 366, 39693987, doi:10.1098/rsta.2008.0137, 2008.

Leemans, R., Agrawala, S., Edmonds, J. A., MacCracken, M. C., Moss, R., and Ramakrishnan, P. S.: Mitigation: Cross-Sectoral and Other Issues, 799-819, Chapter 25, in: Climate Change 1995: Impacts, Adaptations and Mitigation of Climate Change: Scientific-Technical Analyses, Contribution of Working Group II to the Second Assessment Report of the Intergovernmental Panel on Climate Change, edited by: Watson, R. T., Zinyowera, M. C., and Moss, R. H., Cambridge University Press, Cambridge, UK, 879 pp., 1995.

Lenton T. M., Held, H., Kriegler, E., Hall, J. W., Lucht, W., Rahmstorf, S., and Schellnhuber, H. J.: Tipping elements in the Earth's climate system, P. Natl. Acad. Sci. USA, 105, 17861793, doi:10.1073/pnas.0705414105, 2008.

Long J., Rademaker, S., Anderson, J. G., Caldeira, K., Chaisson, J., Goldston, D., Hamburg, S., Keith, D., Lehman, R., Loy, F., Morgan, G., Sarewitz, D., Schelling, T., Shepherd, J., Victor, D., Whelan, D., and Winickoff, D. E.: Task Force on Climate Remediation Research, Bipartisan Policy Center, Washington, D.C., 33 pp., 2011

MacCracken, M. C.: On the possible use of geoengineering to moderate specific climate change impacts, Environ. Res. Lett., 4, 045107, doi:10.1088/1748-9326/4/4/045107, 2009.

MacCracken, M. C.: Potential applications of climate engineering technologies to moderation of critical climate change impacts, IPCC Expert Meeting on Geoengineering, 20-22 June 2011, Lima, Peru, 55-56, in: Meeting Report, edited by: Edenhofer, O., Pichs-Madruga, R., Sokona, Y., Field, C., Barros, V., Stocker, T. F., Dahe, Q., Minx, J., Mach, K., Plattner, G.-K., Schlömer, S., Hansen, G., and Mastrandrea, M., Intergovernmental Panel on Climate Change, Geneva, Switzerland, 2011.

MacMartin, D. G., Keith, D. W., Kravitz, B., and Caldeira, K.: Management of trade-offs in geoengineering through optimal choice of non-uniform radiative forcing, Nat. Clim. Change, 3, 365-368, 2013.

Meier, M. F., Dyurgerov, M. B., Rick, U. K., O’Neel, S., Pfeffer, W. T., Anderson, R. S., Anderson, S. P., and Glazovsky, A. F.: Glaciers dominate eustatic sea-level rise in the 21 st century, Science 317, 1064-1067, doi:10.1126/science.1143906, 2007.

Meinshausen, M., Meinshausen, N., Hare, W., Raper, S. C. B., Frieler, K., Knutti, R., Frame, D. J., and Allen, M. R.: Greenhouse-gas emission targets for limiting global warming to $2{ }^{\circ} \mathrm{C}$, Nature, 458, 1158-1162, doi:10.1038/nature08017, 2009.

Mitchell, D. L. and Finnegan, W.: Modification of cirrus clouds to reduce global warming, Environ. Res. Lett., 4, 045102, doi:10.1088/1748-9326/4/4/045102, 2009.
Murphy, D. M.: Constraining climate sensitivity with linear fits to outgoing radiation, Geophys. Res. Lett., 37, L09704, doi:10.1029/2010GL042911, 2010.

NAS - National Academy of Sciences: Policy Implications of Greenhouse Warming: Mitigation, Adaptation, and the Science Base, National Academy Press, Washington, D.C., 918 pp., 1992.

NRC - National Research Council: America's Climate Choices: Advancing the Science of Climate Change, National Academy Press, Washington, D.C., 528 pp., 2010.

Overland, J. E., Francis, J. A., Hanna, E., and Wang, M.: The recent shift in early summer Arctic atmospheric circulation, Geophys. Res. Lett., 39, L19804, doi:10.1029/2012GL053268, 2012.

Pierce, J. R., Weisenstein, D. K., Heckendorn, P., Peter, T., and Keith, D. W.: Efficient formation of stratospheric aerosol for geoengineering by emission of condensible vapor from aircraft, Geophys. Res. Lett., 37, L18805, doi:10.1029/2010GL043975, 2010.

PIK - Potsdam Institute for Climate Impact Research and Climate Analytics: Turn Down the Heat: Why a $4{ }^{\circ} \mathrm{C}$ Warmer World Must be Avoided, report for the World Bank, Washington, D.C., 94 pp. 2012.

PIK - Potsdam Institute for Climate Impact Research and Climate Analytics: Turn Down the Heat: Climate Extremes, Regional Impacts, and the Case for Resilience, report for the World Bank, Washington, D.C., 238 pp., 2013.

PSAC - President's Science Advisory Committee: Appendix Y4: Atmospheric Carbon Dioxide, 111-133, in: Restoring the Quality of our Environment, Report of the Environmental Pollution Panel, The White House, Washington, D.C., 317 pp., 1965.

Pritchard, H. D., Ligtenberg, S. R. M., Fricker, H. A., Vaughan, D. G., van den Broeke, M. R., and Padman, L.: Antarctic ice-sheet loss driven by basal melting of ice shelves, Nature 484, 502-505, doi:10.1038/nature10968, 2012.

Rahmstorf, S.: A semi-empirical approach to projecting future sealevel rise, Science, 315, 368-370, 2007.

Rasch, P. J., Crutzen, P. J., and Coleman, D. B.: Exploring the geoengineering of climate using stratospheric sulfate aerosols: The role of particle size, Geophys. Res. Lett., 35, L02809, doi:10.1029/2007GL032179, 2008a

Rasch, P. J., Tilmes, S., Turco, R. P., Robock, A., Oman, L., Chen, C.-C., Stenchikov, G. L., and Garcia, R. R.: An overview of geoengineering of climate using stratospheric sulfate aerosols, Philos. T. Roy. Soc. A, 366, 4007-4037, doi:10.1098/rsta.2008.0131, 2008b.

Rasch, P. J., Latham, J., and Dhen, C.-C.: Geoengineering by cloud seeding: Influence on sea ice and climate system, Environ. Res. Lett., 4, 045112, doi:10.1088/1748-9326/4/4/045112, 2009.

Rayner, S., Redgwell, C., Savulescu, J., Pidgeon, N., and Kruger, T.: Memorandum on draft principles for the conduct of geoengineering research (the "Oxford Principles"), reproduced in House of Commons Science and Technology Committee, The Regulation of Geoengineering, Fifth Report of the Session 200910, HC 221, 18 March 2010, see: www.publications.parliament. uk/pa/cm200910/cmselect/cmsctech/221/221.pdf (last access: 19 July 2012), 2010.

Robock, A.: 20 reasons why geoengineering may be a bad idea, Bull. Atomic. Sci., 64, 14-18, doi:10.2968/064002006, 2008. 
Robock, A., Oman, L., and Stenchikov, G.: Regional climate responses to geoengineering with tropical and Arctic $\mathrm{SO}_{2}$ injections, J. Geophys. Res., 113, D16101, doi:10.1029/2008JD010050, 2008.

Robock, A., Marquardt, A. B., Kravitz, B., and Stenchikov, G.: The benefits, risks, and costs of stratospheric geoengineering, Geophys. Res. Lett., 36, L19703, doi:10.1029/2009GL039209, 2009.

Schneider, S. H.: Earth systems: Engineering and management, Nature, 409, 417-421, 2001.

Seitz, R.: Bright water: hydrosols, water conservation and climate change, Climatic Change, 105, 365-381, doi:10.1007/s10584010-9965-8, 2011.

Shepherd, J., Caldeira, K., Cox, P., Haigh, J., Keith, D., Launder, B., Mace, G., MacKerron, G., Pyle, J., Rayner, S., Redgwell, C., Watson, A., Garthwaite, R., Heap, R., Parker, A., and Wilsdon, J.: Geoengineering the Climate: Science, Governance and Uncertainty, Science Policy Centre of The Royal Society, London, UK, 98 pp., 2009.
Truffer, M. and Fahnestock, M.: Rethinking Ice Sheet Time Scales, Science, 315, 1508-1510, doi:10.1126/science.1140469, 2007.

Valero, F. P. J., Ackerman, T. P., and Gore, W. J. Y.: The absorption of solar radiation by the Arctic atmosphere during the haze season and its effects on the radiation balance, Geophys. Res. Lett., 11, 465-468, doi:10.1029/GL011i005p00465, 1984.

Wigley, T. M. L.: A combined mitigation/geoengineering approach to climate stabilization, Science, 314, 452-454, doi:10.1126/science.1131728, 2006.

Winton, M.: Surface albedo feedback estimates for the AR4 climate models, J. Climate, 19, 359-365, 2005.

Winton, M.: Amplified Arctic climate change: What does surface albedo feedback have to do with it?, Geophys. Res. Lett., 33, L03701, doi:10.1029/2005GL025244, 2006.

Zwiers, F. W. and von Storch, H.: Taking serial correlation into account in tests of the mean, J. Climate, 8, 336-351, 1995. 